\title{
The Importance of Phenolic Metabolism to Limit the Growth of Phakopsora pachyrhizi
}

\author{
Anatoliy V. Lygin, Shuxian Li, Ramya Vittal, Jack M. Widholm, Glen L. Hartman, and Vera V. Lozovaya
}

First, third, fourth, and sixth authors: Crop Sciences Department, University of Illinois at Urbana-Champaign, 1201 W. Gregory Dr., Urbana 61801; second author: United States Department of Agriculture-Agricultural Research Service (USDA-ARS), Crop Genetics \& Production Research Unit, Stoneville, MS 38776; and fifth author: USDA-ARS and Department of Crop Sciences, University of Illinois, 1101 W. Peabody Dr., Urbana 61801. Accepted for publication 13 June 2009.

\begin{abstract}
Lygin, A. V., Li, S., Vittal, R., Widholm, J. M., Hartman G. L., and Lozovaya, V. V. 2009. The importance of phenolic metabolism to limit the growth of Phakopsora pachyrhizi. Phytopathology 99:1412-1420.

Understanding the metabolic responses of the plant to a devastating foliar disease, soybean rust, caused by Phakopsora pachyrhizi, will assist in development of cultivars resistant to soybean rust. In this study, differences in phenolic metabolism were analyzed between inoculated and noninoculated plants using two susceptible and three resistant soybean genotypes with known resistance genes. Rust infection resulted in increased accumulation of isoflavonoids and flavonoids in leaves of all soybean genotypes tested. Although the soybean phytoalexin glyceollin

compound at marked levels occurred in rust-infected leaves, being substantially higher in genotypes with a red-brown resistant reaction. In addition, there was inhibition of $P$. pachyrhizi spore germination by glyceollin, formononetin, quercetin, and kaempferol. However, there was no correlation between concentrations of flavonoids quercetin and kaempferol and rust-induced isoflavonoid formononetin in soybean leaves and rust resistance. Lignin synthesis also increased in all inoculated soybean genotypes whereas there was no significant difference in all noninoculated soybean genotypes. Cell wall lignification was markedly higher in inoculated resistant lines compared with inoculated susceptible lines, indicating a possible protective role of lignin in rust infection development.
\end{abstract} was not detected in leaves of uninfected plants, accumulation of this
Soybean rust, caused by Phakopsora pachyrhizi Syd. \& P. Syd., has been widely distributed throughout the tropics and subtropics of Asia for many decades (25). More recently, the pathogen was reported in Africa (32), South America (54), and Hawaii (30). Since the first report in the continental United States in 2004 (49), the occurrence of soybean rust has been intensely monitored by various groups reporting back to a central location (50).

The sources of resistance and the genetics of resistance of the four single dominant genes (Rppl to -4) to specific soybean rust isolates were reviewed (24). In addition, Rpp5 was recently identified (11) along with a new allele of Rppl (12). Resistance to $P$. pachyrhizi in soybean occurs when no visual lesions are observed or when red-brown (RB) lesions develop, while a susceptible response occurs when tan lesions develop $(8,9)$. A number of reports indicated that these four single dominant genes (Rppl to -4) are not effective when challenged with different isolates of $P$. pachyrhizi $(7,38,44)$. For example, when each of the known resistance sources (Rppl to -4 ) were challenged with three domestic U.S. P. pachyrhizi isolates, PI200492 (Rppl) and PI462312 (Rpp3) produced a differential response while PI230970 (Rpp2) and PI459025B (Rpp4) produced RB lesions (44).

In order to combat pathogens, higher plants have evolved a complicated system of innate immunity that can provide a plant defense against pathogens (48). The multilevel net of structural and chemical barriers that are both preformed (constitutive) and inducible may involve compounds that could strengthen the plant cell wall, cause a hypersensitive response (HR) and oxidative burst, and be involved in the synthesis of phytoalexins and patho-

Corresponding author: V. V. Lozovaya; E-mail address: lozovaya@illinois.edu

doi:10.1094/PHYTO-99-12-1412

(c) 2009 The American Phytopathological Society genesis-related (PR) proteins $(5,46)$. To cause disease, the pathogen must successfully overcome these barriers and obstacles through modification of plant metabolism to its own benefit or by abolishing the defense responses. Little is known about the metabolic responses of soybean plants to $P$. pachyrhizi.

The abundance of soybean mRNAs was recently compared between the soybean Rpp2-resistant genotype PI230970 and the highly susceptible genotype Embrapa-48 after rust infection using microarray analysis, and an overrepresentation of genes associated with secondary metabolism was found (40). The authors analyzed expression of the phenylpropanoid pathway genes that are important for plant defense and found that increased expression of selected genes of phenylpropanoid metabolism occurred 1 to 2 days earlier in PI230970 than in the susceptible plants, showing that differential gene expression occurred during those two types of interactions.

Our previous studies of soybean plant-pathogen interactions showed that soybean resistance to fungal diseases such as sudden death syndrome (SDS) was correlated with the levels of the antibiotic-like phytoalexin glyceollin, which is formed via the phenylpropanoid pathway (34). The pathogen-inducible phenylpropanoid phytoalexins play a crucial role in plant disease resistance and they were found in many plant species, including legumes $(13,14,29,34,35)$. The importance of glyceollin in providing soybean resistance against Phytophthora sojae Kaufm. \& Gerd. was demonstrated in different studies $(1,3,6,16,22,55)$. We have found that glyceollin is also toxic to many other important soybean fungal pathogens (A. V. Lygin, C. B. Hill, O. V. Zernova, J. M. Widholm, G. L. Hartman, and V. V. Lozovaya, unpublished).

In addition to glyceollin, lignin is a well-studied plant cell wall aromatic polymer (formed by oxidative polymerization of $\mathrm{p}$ coumaryl, coniferyl, and sinapyl alcohols) that helps to provide a barrier to fungal entry into plant tissues and to the diffusion of 
toxins and enzymes which fungi secrete in advance of invasion to prepare or soften the plant cells for colonization $(10,18,51)$. Synthesis of antimicrobial phytoalexins and cell wall reinforcement (due to synthesis of various wall-bound phenolic compounds) is part of a plant's innate or basal resistance that helps prevent infection by most fungi.

It is important to learn what metabolic pathways in soybean plants are involved in response to Phakopsora pachyrhizi and what metabolic differences exist between infected plants with different susceptibilities to $P$. pachyrhizi in order to assist in the development of improved cultivars that produce more stable yields under different environmental conditions. Our present study describes how the fungus alters phenolic metabolism in plants that are highly susceptible or partially resistant to rust and which specific phenylpropanoids could inhibit fungal growth and development.

\section{MATERIALS AND METHODS}

Plant materials and inoculation. Two susceptible soybean cultivars (Williams and Williams 82) and three plant introductions (PI200492, PI230970, and PI462312) with known single genes (Rppl to -3 , respectively) for resistance to $P$. pachyrhizi were tested. The experiment was a randomized complete block design (RCBD). Five soybean lines were blocked and randomized in three replications. Each experimental unit was five plants of each line, in which five seeds were sown in a $10-\mathrm{cm}$ pot with three replicates (pots).

Inoculation was performed on 21-day-old seedlings. Inoculum was prepared using freshly collected urediniospores from Williams 82. Spore suspensions were made using sterile distilled water containing $0.01 \%$ Tween-20 ( $\mathrm{vol} / \mathrm{vol})$, mixed, and filtered through a $100-\mu \mathrm{m}$ cell strainer (BD Biosciences, Bedford, MA) to remove any debris and clumps of urediniospores. Urediniospores were quantified using a hemacytometer and diluted to a final concentration of 40,000 per milliliter. Inoculation was at the rate of $1 \mathrm{ml}$ of spore suspension per plant and applied with a Preval sprayer (Precision Valve Corp., Yonkers, NY). After inoculation, plants were placed in a dew chamber in the dark at $22^{\circ} \mathrm{C}$ overnight $(\approx 16 \mathrm{~h})$ and then moved to a greenhouse bench where temperatures were maintained at $23 \pm 2{ }^{\circ} \mathrm{C}$ with natural light. The same solution minus spores was used for the mock inoculation on three pots of plants of each entry that were placed in another rustfree greenhouse as controls. Experiments were repeated once and performed from November 2006 through February 2007.

The first trifoliate leaves were taken 1 and 3 weeks after inoculation and soluble phenolic compounds were extracted by $80 \%$ methanol. Residues after extraction of soluble phenolics were used for preparation of cell walls.

A bulk population of $P$. pachyrhizi isolates used for inoculation of plants in the greenhouse was obtained from urediniospores harvested from numerous pustules on field-collected kudzu leaves in Jefferson County, MS in August 2006. The soybean rust-causal pathogen was confirmed by microscopy, enzyme-linked immunosorbent assay, and polymerase chain reactions as previously described (33). Urediniospores were increased on susceptible soybean cv. Williams 82 in the Stoneville, MS Research Quarantine Facility.

Spore germination tests in liquid medium and on detached leaves. To test the effect of selected phenolic compounds on $P$. pachyrhizi spore germination, 96-well plates were prepared containing either ethanol at $100 \mathrm{nmol} / \mathrm{ml}$ (control 1) or dimethyl sulfoxide (DMSO) at $100 \mathrm{nmol} / \mathrm{ml}$ (control 2) in water and one of the phenolic compounds tested (quercetin, kaempferol, formononetin, and glyceollin at 50 to $200 \mathrm{nmol} / \mathrm{ml}$ ). In each well, a $10 \mu \mathrm{l}$ drop of $\approx 50$ urediniospores of a single-spore stock of $P$. pachyrhizi isolate Florida 07-1 was dispensed. The plates were incubated in the dark at $22^{\circ} \mathrm{C}$ and germination recorded at $12 \mathrm{~h}$ after incubation. Quercetin, kaempferol, and formononetin were purchased from Indofine Chemical Company Inc., Hillsborough, NJ. Glyceollins (a mixture of glyceollins I, II, and III) were produced in bulk from soybean cotyledons infected with $P$. megasperma as described (3) by extraction with $95 \%$ ethanol followed by partial purification using liquid chromatography on silica gel (column size: $35 \mathrm{~cm}$ length and $2.5 \mathrm{~cm}$ in diameter). Glyceollins were eluted with $200 \mathrm{ml}$ of solvent (hexane-ethyl acetate, 60:40 [vol/vol]), and the column fractions with high absorbance at $285 \mathrm{~nm}$ were collected. The purity of glyceollins obtained (not less than 95\%) was confirmed by high-performance liquid chromatography (HPLC).

Spores of $P$. pachyrhizi used in spore germination tests with detached leaves were freshly collected from soybean detached leaves and suspended in $0.01 \%$ Tween 20 at 70 spores/ $\mu$ l. Fifteen 10-day-old Williams 82 leaves were used and each leaf was treated with fungal spores and also with one of the following phenolic compounds at different concentrations ( 1 to 50, 2 to 100, and 3 to $200 \mathrm{nmol} / \mathrm{ml}$ ): kaempferol, formononetin, and glyceollin; plus two controls under two different conditions: pre-inoculation and postinoculation. Each treatment was a $20-\mu \mathrm{l}$ drop containing $10 \mu \mathrm{l}$ of spore suspension and $10 \mu \mathrm{l}$ of phenolic compound. The first $10-\mu \mathrm{l}$ droplet was allowed to dry and followed by the addition of the second droplet on the same spot (for pre-inoculation, the droplet with the compound was applied before the spore droplet and, for postinoculation, the spores were applied and then the compounds). Data were collected as presence of uredinia or absence of uredinia. Plates were scored starting from the day that controls showed uredinia. For analysis of urediniospore germination, the tests were an RCBD with four replications. Analyses of variance were performed with JMP (version 7; SAS Institute Inc., Cary, NC). Least square estimates of means were detransformed for presentation of rust incidence in the accompanying tables and figures.

Extraction and analysis of phenolic compounds. Soybean leaves $(0.15$ to $0.35 \mathrm{~g}$ fresh weight) fixed in $1 \mathrm{ml}$ of $80 \%$ methanol were ground using mortar and pestle and the suspension was transferred to tubes to the final volume of $5 \mathrm{ml}$.

Isoflavonoids were analyzed by HPLC according to Lozovaya et al. (34) using Hypersil BDS (Alltech, Deerfield, IL), 150 by $4.6 \mathrm{~mm}, 3 \mu \mathrm{m}$, flow rate $=1.2 \mathrm{ml} / \mathrm{min}, \mathrm{T}_{\text {column }}=30^{\circ} \mathrm{C}$. A linear gradient composed of water (adjusted with acetic acid to $\mathrm{pH} 2.8$ ) and acetonitrile was used. Following injection of 10 to $20 \mu \mathrm{l}$ of sample, acetonitrile was increased from 8 to $20 \%$ over $15 \mathrm{~min}$, held for $4 \mathrm{~min}$, and increased to $60 \%$ over $6 \mathrm{~min}$.

Glucosyl conjugates of quercetin and kaempferol were analyzed using the same system and were identified by UV spectra ( $\lambda_{\max } 255.6 \mathrm{~nm}$ and 355 to $358 \mathrm{~nm}$ for quercetin; $\lambda_{\max } 266 \mathrm{~nm}$ and 346 to $348 \mathrm{~nm}$ for kaempferol) and by tandem mass spectroscopy (MS-MS) (data not shown). Peak areas of glucosyl conjugates were determined, combined for quercetin and kaempferol, calculated per gram fresh weight of leaf sample, and presented as a relative abundance of these compounds. The system used for liquid chromatography (LC)-MS analysis of (iso)flavonoids was a Finnigan LCG Deca XP ion trap mass spectrometer (Thermo Fisher Scientific Inc.) coupled with a 2695 Module and PDA 996 detector (Waters Corp., Milford MA). Electrospray ionization (ESI) was used. The capillary was heated to $225^{\circ} \mathrm{C}$ and voltage was $4.5 \mathrm{kV}$. The full-scan mass spectra of the (iso)flavonoids were $\mathrm{m} / \mathrm{z} 100$ to 1,000 . Helium as collision gas was used for MS-MS and collision energy was set at $35 \%$.

Lignin measurement. Acetyl bromide lignin in soybean leaves was determined according to Fukushima and Hartfield (21). Alcohol insoluble residues $(\approx 10 \mathrm{mg}$ ) obtained by centrifugation of samples after soluble phenolic extraction were used for lignin measurements. The lignin content of samples was calculated using the specific absorption coefficient (SAC) of $20 \mathrm{~g}^{-1} \mathrm{~cm}^{-1}$ for lignin and the following equation: percent lignin content = 
(absorbance $\times 100) / \mathrm{SAC} \times$ sample concentration $\left(\mathrm{g}^{-1}\right)$, as described previously (47).

\section{RESULTS AND DISCUSSION}

Changes in soluble and cell-wall-bound phenylpropanoids of rust-infected leaves. Rust infection resulted in a typical susceptible $(\tan )$ reaction in the susceptible genotypes Williams and Williams 82, while PI230970 (Rpp2) and PI462312 (Rpp3) had RB resistant reactions. No soybean rust lesions were found on PI200492 (Rppl).

An increased accumulation of the isoflavonoids genistein (Fig. 1) and daidzein (Fig. 2) occurred in leaves of almost all soybean lines tested after inoculation with the $P$. pachyrhizi isolate compared with the noninoculated control both 1 and 3 weeks after inoculation, and much greater increase was found 3 weeks after inoculation. However, there was not a significant difference in the genistein levels between noninoculated and inoculated leaves of PI462312 1 week after inoculation. Fungal infection often leads to transcriptional activation of phenolic biosynthetic genes and increased contents of isoflavonoids and flavonoids (53). Although the antibiotic-like phytoalexin glyceollin was not detected in leaf samples of noninoculated control plants of all genotypes tested, we found low and similar concentrations 1 week after inoculation (when there was no visual infection on inoculated leaves in all genotypes). Glyceollin accumulated to high concentrations in rust-infected leaves 3 weeks after inoculation, especially in the resistant genotypes, indicating that this phytoalexin is involved in the plant defense response to the soybean rust pathogen (Fig. 3). Our past studies of soybean plant-pathogen interactions showed that invasion by fungi, such as Fusarium solani f. sp. glycines (syn. F. virguliforme) (2) that causes SDS, was more aggressive in plants of genotypes that produced lower levels of the phytoalexin glyceollin and less damaging in plants of genotypes with higher

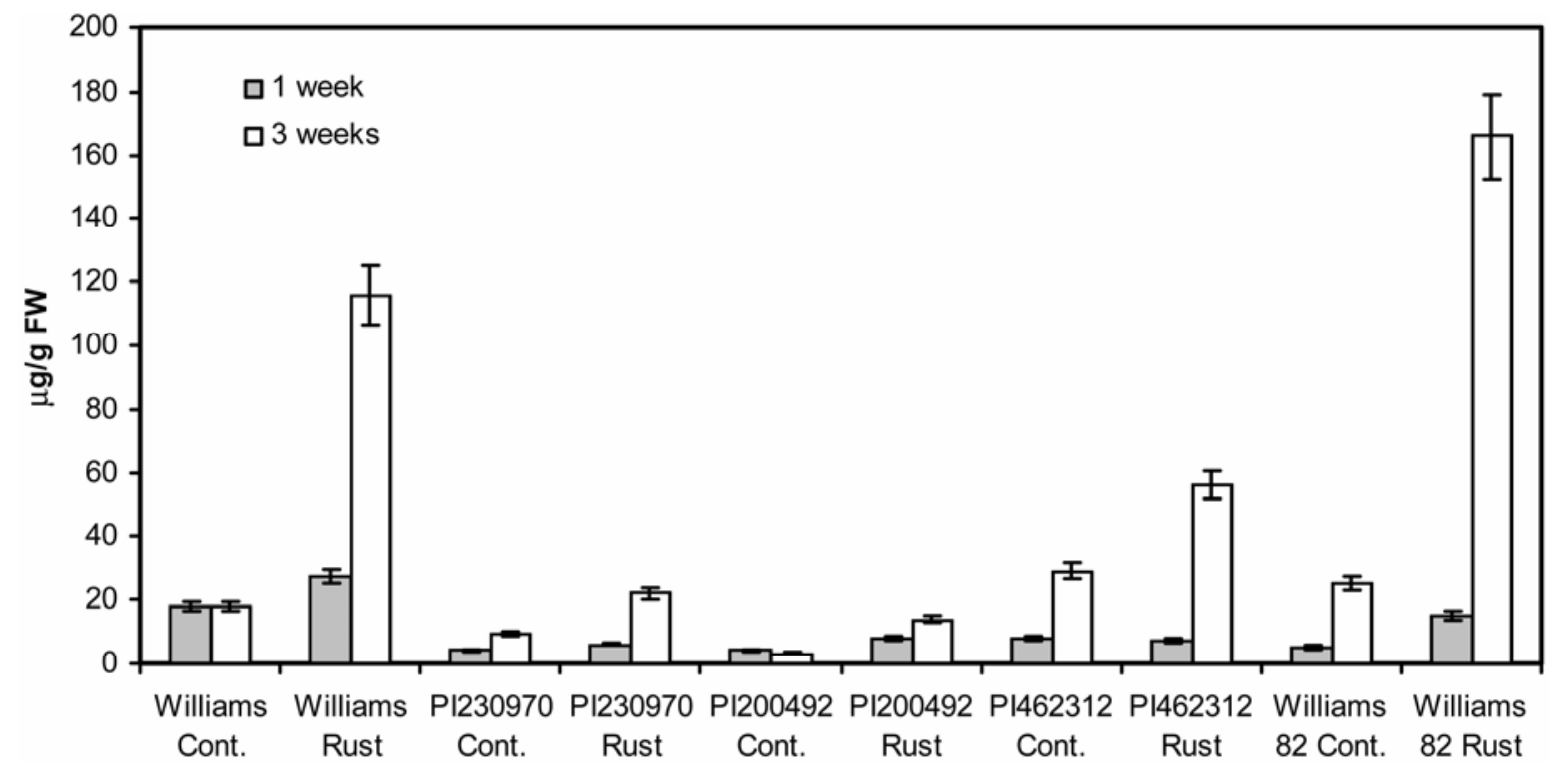

Fig. 1. Genistein concentrations in Phakopsora pachyrhizi inoculated and noninoculated (control) soybean leaves of different genotypes 1 or 3 weeks after inoculation. Data are average of three replicates of representative from two independent experiments. Bars show standard errors.

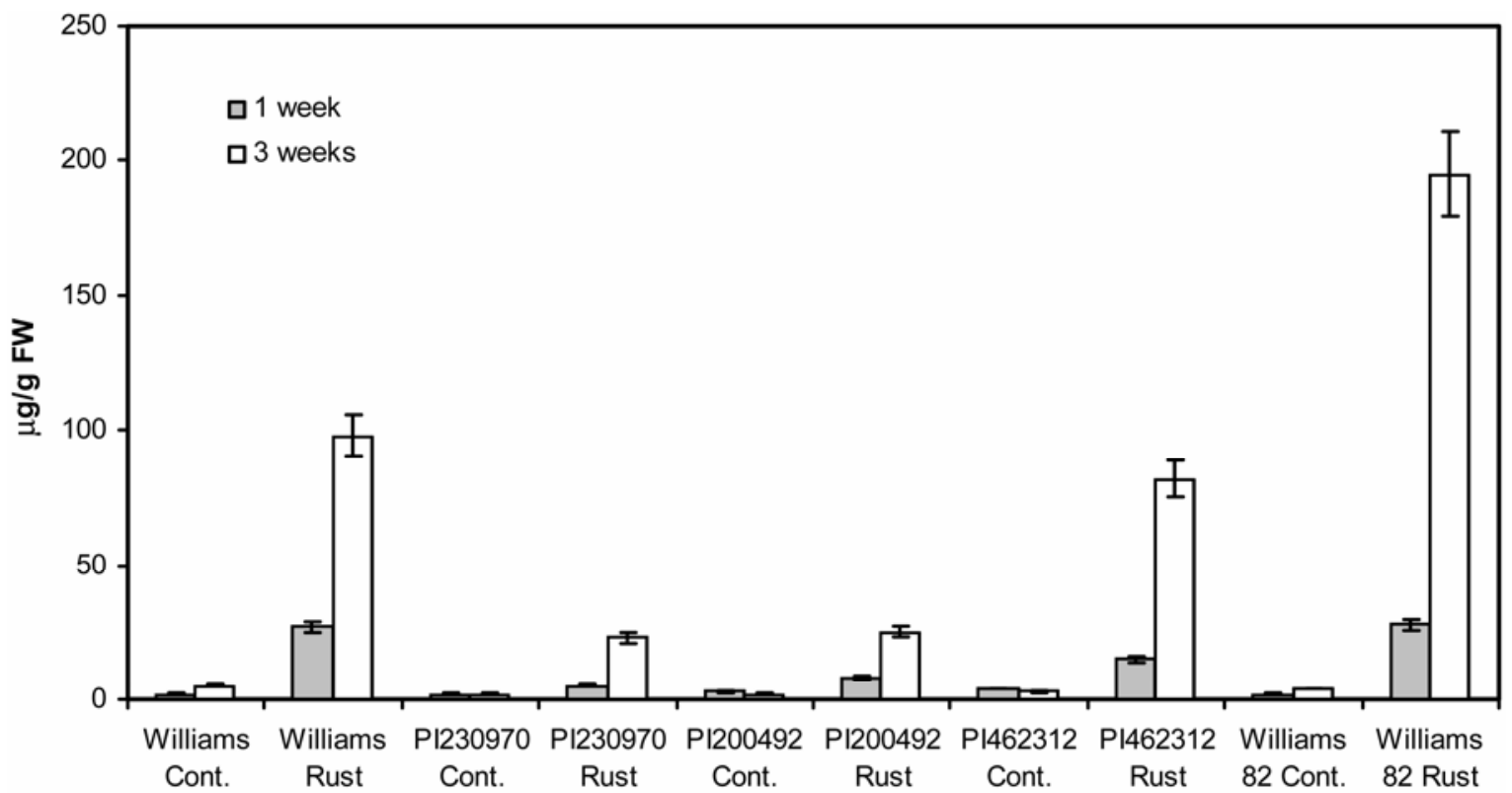

Fig. 2. Daidzein concentrations in Phakopsora pachyrhizi inoculated and noninoculated (control) soybean leaves of different genotypes 1 or 3 weeks after inoculation. Data are average of three replicates of representative from two independent experiments. Bars show standard errors. 
levels of glyceollin in roots (34). The concentration-dependent fungicidal effects of glyceollin on $F$. virguliforme have also been reported previously, (34) when we found a reduction of $F$. virguliforme growth after exposure to glyceollin at concentrations of 25 to $215 \mathrm{nmol} / \mathrm{ml}$ (which were comparable with those detected in the inoculated roots, 300 to $600 \mathrm{nmol} / \mathrm{ml}$ ) with a response being different for different fungal isolates.

Very low concentrations of the precursor of glyceollin, daidzein, were found in noninoculated plant leaves and several-fold higher daidzein concentrations were detected in rust-infected leaves of all soybean lines tested 1 week after inoculation, and this increased further 3 weeks after inoculation (Fig. 2). Even though the total daidzein concentration was higher in rust-susceptible genotypes Williams and Williams 82, greater accumulation of glyceollin occurred in genotypes that contained less daidzein but had better rust resistance, which could indicate more rapid conversion of daidzein to glyceollin in rust-tolerant lines. Daidzein concentrations in soybean tissues have previously been reported to essentially exceed the level required for a $50 \%$ effective dose accumulation of glyceollin (23). One should also keep in mind that soy isoflavones are phenolic compounds that almost exclusively exist in a latent form as conjugates, $\beta$-glucosides, and $\beta$ glucoside conjugated with malonyl groups (23). In order to interact with pathogens, these conjugates must be converted to aglycons and the $\beta$-glucosidases are a heterogeneous group of enzymes which hydrolyse $\beta$-glucosidic links of glucosides conjugates releasing glucose (26). It is possible that the $\beta$-glucosidase activities were different in genotypes studied here, providing different concentrations of daidzein aglycon for glyceollin synthesis. It should be noted in relation to this assumption that the global microarray analysis showed that glycosyl hydrolases were among upregulated genes in soybean leaf samples inoculated to cause rust infection (42).

We have already reported that, after inoculation with SDScausing fungus, glyceollin accumulated to much lower concentrations in roots of the SDS-susceptible cv. Spencer than in the partially resistant genotype PI567374, in spite of the fact that daidzein concentrations were higher in noninfected roots of Spencer, both in the roots of plants grown in greenhouse (34) and in hairy roots $(35,36)$. These results clearly indicate that meta- bolic steps after daidzein control accumulation of the phytoalexin glyceollin in soybean.

Concentration of genistein in noninoculated leaves exceeded that of daidzein and notably increased in leaves of Williams and Williams 82 in response to rust infection (Figs. 1 and 2), although there were no significant changes of genistein concentration in other genotypes tested, so that a role of this isoflavonoid in soybean rust response remains unclear.

Our data also show that rust infection caused changes in concentrations of other phenylpropanoids in inoculated leaves. HPLC analysis of methanol extracts of soybean leaves with $P$. pachyrhizi gave two peaks with $\mathrm{R}_{\mathrm{t}}=32.6$ and $33.0 \mathrm{~min}$ that have the same UV spectra $\left(\lambda_{\max } 249 \mathrm{~nm}\right)$ and were identical to formononetin (Fig. 4). Intensity of the first peak was 0 to $10 \%$ that of the second peak. We assumed that these compounds were formononetin (7hydroxy-4'-metoxyisoflavone) and isoformononetin (7-metoxy4'-hydroxyisoflavone). Co-elution of leave extract with commercial standard of formononetin resulted in an increase in the second peak. We applied LC-MS-MS for final identification of these compounds. ESI-LC-MS of first peak $\left(\mathrm{R}_{\mathrm{t}}=32.6 \mathrm{~min}\right)$ gave pseudomolecular ion at $\mathrm{m} / z, 269[\mathrm{M}+\mathrm{H}]^{+}$. MS-MS of this ion gave fragments at $\mathrm{m} / z, 251\left[\mathrm{M}+\mathrm{H}-\mathrm{H}_{2} \mathrm{O}\right]^{+}, 241[\mathrm{M}+\mathrm{H}-\mathrm{CO}]^{+}$, and 213 $[\mathrm{M}+\mathrm{H}-\mathrm{CO}-\mathrm{CO}]^{+}$and an ion at 151 (Fig. 4) as a result of retro Diels Alder fragmentation of isoformononetin (37). The second peak $\left(\mathbf{R}_{\mathbf{t}}=33.0 \mathrm{~min}\right)$ gave the same pseudomolecular ion at $\mathrm{m} / \mathrm{z}$ 269 as the first peak did. MS-MS fragments of this ion were at $m / z, 255\left[\mathrm{M}+\mathrm{H}-\mathrm{CH}_{3}\right]^{+}, 241[\mathrm{M}+\mathrm{H}-\mathrm{CO}]^{+}, 237\left[\mathrm{M}+\mathrm{H}-\mathrm{CH}_{3} \mathrm{OH}\right]^{+}$, $213[\mathrm{M}+\mathrm{H}-\mathrm{CO}-\mathrm{CO}]^{+}$, and 135 after retro Diels Alder fragmentation of formononetin. The fragment at $\mathrm{m} / z, 151$ could be produced from isoformononetin and the fragment at $\mathrm{m} / \mathrm{z} 135$ could result from formononetin after Diels Alder fragmentation (Fig. 4). Thus, we identified the compound with $\mathrm{R}_{\mathrm{t}}=32.6 \mathrm{~min}$ as isoformononetin (was present only at trace amounts in infected soybean leaves) and the compound with $\mathrm{R}_{\mathrm{t}}=33.0 \mathrm{~min}$ as formononetin.

The isoflavonoid formononetin (Fig. 5) was below detectable amounts $(<50 \mathrm{ng} / \mathrm{g}$ under the sample preparation conditions used here) in leaves of all noninoculated genotypes tested and in inoculated PI230970, PI200492, and PI462312 plants 1 week after inoculation; however, Williams and Williams 82 contained low levels of formononetin 1 week after inoculation and notable

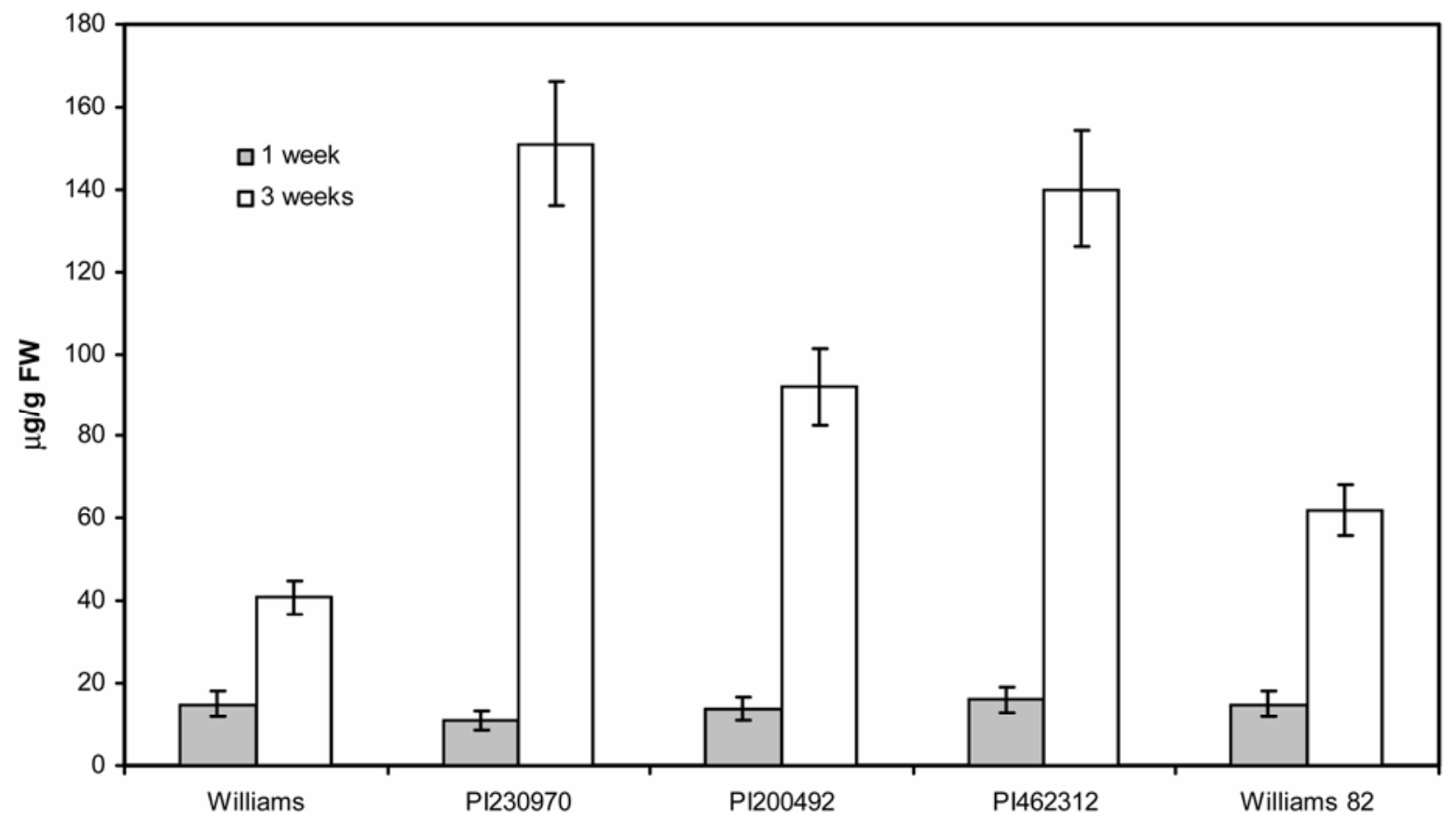

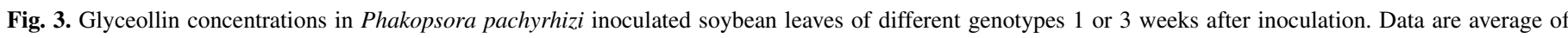
three replicates of representative from two independent experiments. Bars show standard errors. No glyceollin was detected in the noninoculated soybean leaves. 
amounts were found in all plants 3 weeks after inoculation, with the highest concentrations being detected in Williams and Williams 82 (Fig. 5).

Formononetin has been shown to be a biologically active compound with anti-fungal potential in different plants such as alfalfa (15), asparagus (19), and groundnut plants (4), but isoformononetin and formononetin are considered to be the minor inducibly formed isoflavonoids of soybean (28), and glyceollin has been reported as the major inducible soybean phytoalexin formed from daidzein (20). Importantly, the glyceollin concentration was multifold higher than formononetin in rust-inoculated plants in our studies and, apparently, glyceollin was more important and effective than formononetin in reduction of rust disease based on correlation between disease development and glyceollin and formononetin synthesis in genotypes studied here.

In addition, we measured concentrations of the flavonoids quercetin and kaempferol in soybean leaves and found different levels of their glucosyl conjugates in different genotypes. There was no uniform response to rust infection in flavonoid accumulation among genotypes tested (Fig. 6). We found increased concen-
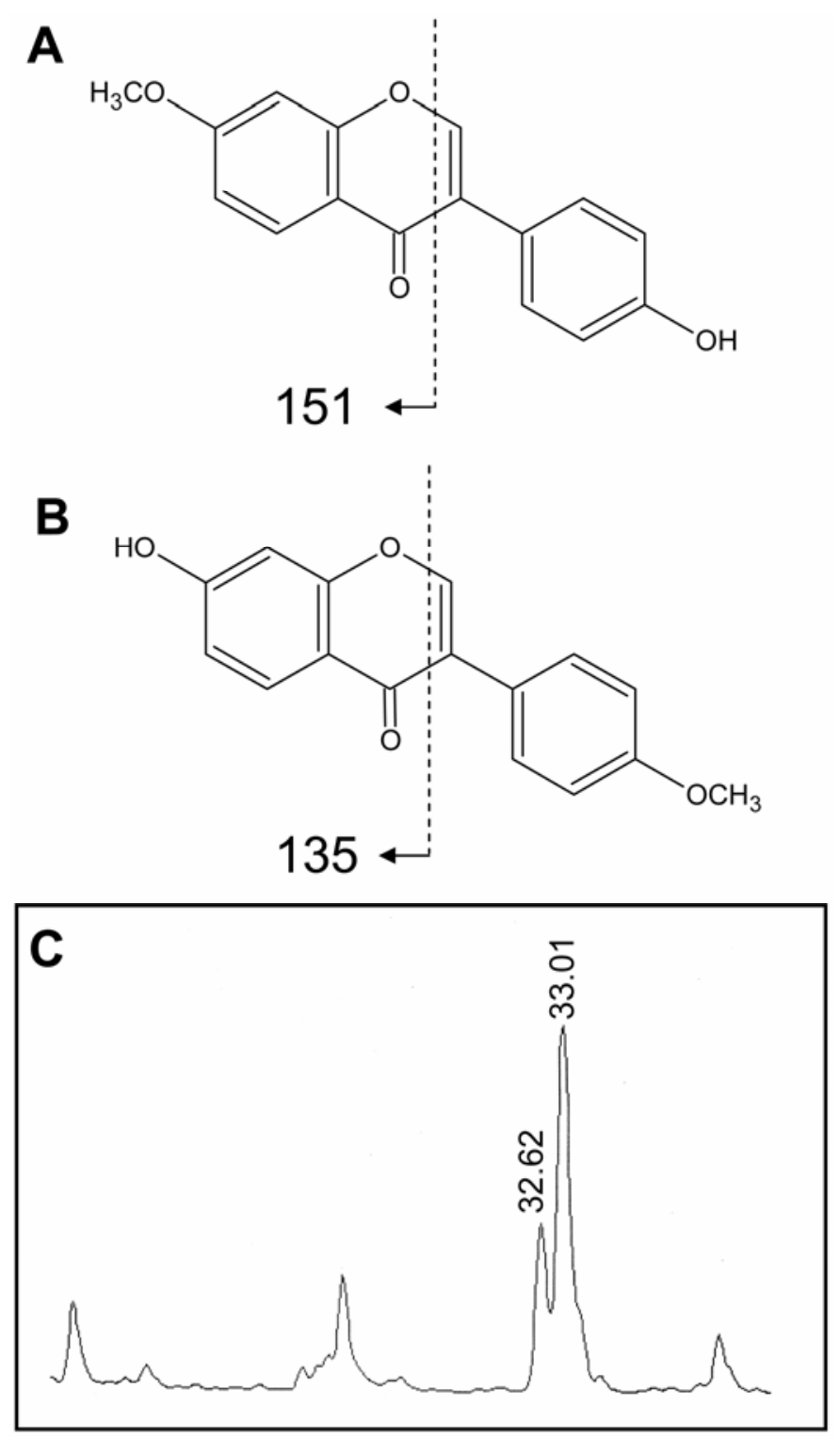

Fig. 4. Tandem mass spectroscopy fragmentation of $\mathbf{A}$, isoformononetin and $\mathbf{B}$, formononetin for identification of two high-performance liquid chromatography peaks with $\mathbf{C}, \mathrm{R}_{\mathrm{t}}=32.6$ and $33.0 \mathrm{~min}$ that had the same UV spectra $\left(\lambda_{\max } 249 \mathrm{~nm}\right)$ and were induced in soybean leaves after inoculation with Phakopsora pachyrhizi. trations of quercetin and kaempferol in leaves of infected rust susceptible genotypes Williams and Williams 82 only 1 week after inoculation and, in all other samples, the contents of these flavonoids did not differ or were lower compared with the corresponding controls. Although flavonoids protect plants against various biotic and abiotic stresses and their increase in plants in response to various types of stresses has been reported (45), we did not see the obvious protective role of quercetin and kaempferol against soybean rust in this study because the increase of these compounds did not correlate with rust resistance.

We also found an increase in acetyl-bromide ( $\mathrm{AcBr}$ ) lignin synthesis in the rust-inoculated plants of all lines tested, with the highest levels of cell wall lignification observed in leaves of the rust-resistant genotypes, especially in PI230970, 3 weeks after inoculation (Table 1). The AcBr lignin content in cell walls of noninoculated plants did not change during the observation times and there were no significant differences in lignin contents between noninoculated leaves of different genotypes. Lignin is one of the most abundant biopolymers on earth, which is important for vascular plant resistance because it strengthens cell wall and protects the structural carbohydrates from microbe degradation and, thus, prevents or delays the microorganism's entry into plant cells and disease progression $(10,17,27,31)$. The association of lignification with plant defense responses to different pathogens has been found in many studies. Plants that accumulated higher levels of lignin in their cell walls had better disease resistance $(41,52)$, and application of specific inhibitors of lignification resulted in the inhibition of the hypersensitive response in wheat plants inoculated with a pathogen (Puccinia graminis) and, thus, caused the development of infection in resistant plants (39). We also demonstrated that the SDS-causing fungus colonized roots of soybean genotypes with higher concentrations of lignin less aggressively than genotypes with lower lignin levels. Because lignin can provide a nondegradable barrier that keeps out most potential pathogens, the lignin level and composition is a major component of plant innate or basal resistance to fungi.

Microarray analysis of rust-inoculated leaves of the soybean genotype PI230970 carrying the Rpp2 gene and a susceptible genotype showed that a number of genes in the phenylpropanoid pathway are rapidly induced $(12 \mathrm{~h})$ and then return to normal, followed by sustained induction after $72 \mathrm{~h}$, especially in PI230970 (40). We did not find changes in phenylpropanoid levels on day 1 (data not shown) but increases could be noted by 1 and 3 weeks after inoculation, which is consistent with the expression data, showing distinct expression profiles for the resistant and susceptible genotypes only at the late infection time frame (40).

Importantly, much greater accumulation of glyceollin and lignin in response to rust inoculation was found in genotypes PI230970 (Rpp2) and PI462312 (Rpp3) that had an RB resistant reaction to rust (Fig. 3; Table 1) compared with susceptible genotypes. Interestingly, PI200492, which was immune to the fungal isolate tested here, accumulated glyceollin and lignin to lower concentrations than the two RB resistant genotypes but higher than susceptible Williams and Williams 82, indicating that the Rppl gene expression rather than induction of glyceollin and lignin synthesis provides immunity to rust infection in these experiments.

Inhibition of Phakopsora pachyrhizi spore germination by phenolic compounds. To investigate whether several phenolic compounds we measured here, glyceollin, formononetin, and kaempferol can affect Phakopsora pachyrhizi spore germination and development, we treated detached 10-day-old Williams 82 leaves with fungal spores and also with one of the selected phenolic compounds using two approaches: phenolic compounds were applied as a small drop to the same spot either before or after inoculation of the spore drop. The control leaves that were not treated with a phenolic compound showed the first uredinia formation 12 days after inoculation and all inoculated control 


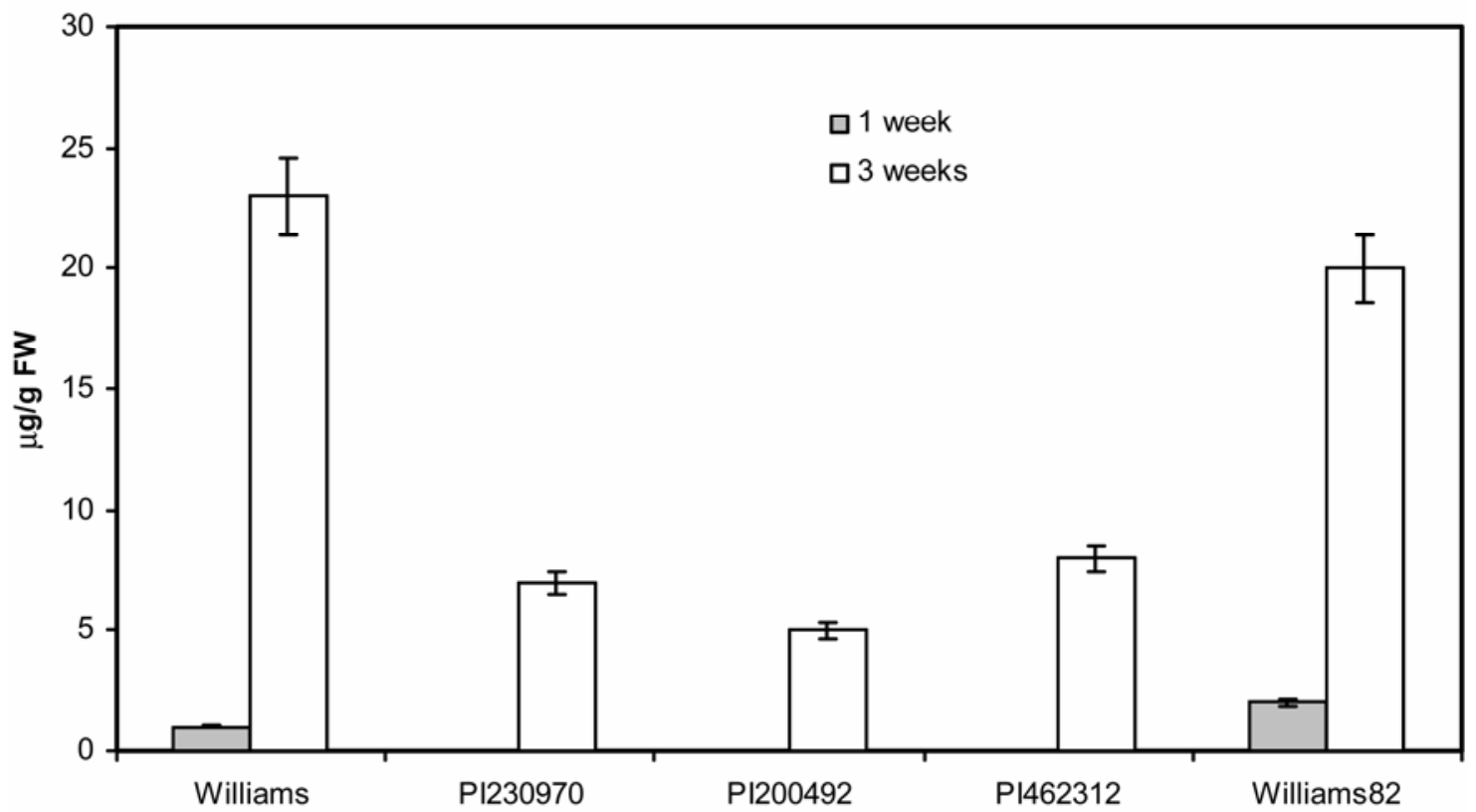

Fig. 5. Formononetin concentrations in Phakopsora pachyrhizi inoculated soybean leaves of different genotypes 1 or 3 weeks after inoculation. Data are average of three replicates of representative from two independent experiments. Bars show standard errors. Formononetin was not detected in the noninoculated soybean leaves.

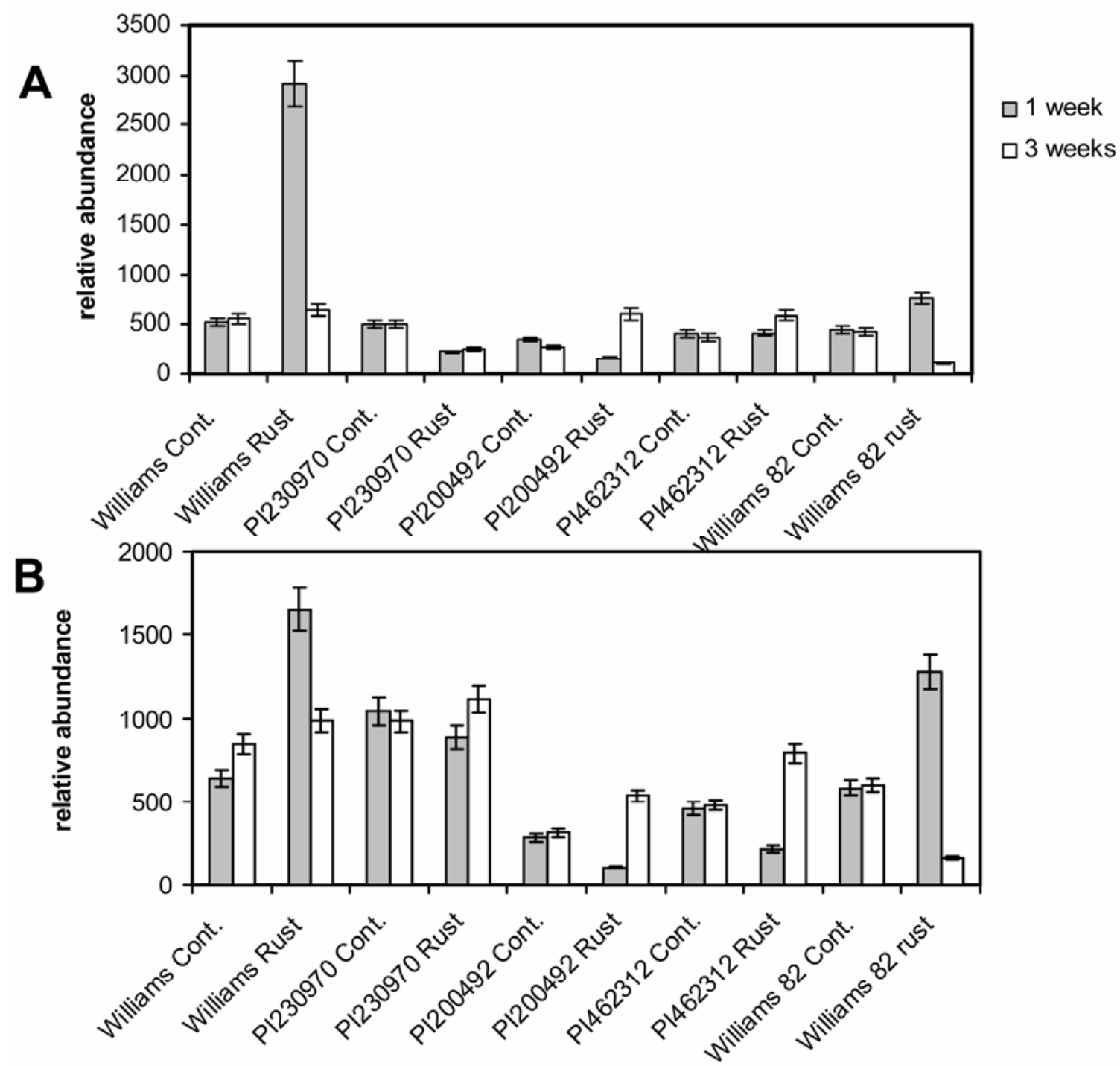

Fig. 6. A, Quercetin and B, kaempferol conjugate levels in Phakopsora pachyrhizi inoculated and noninoculated (control) soybean leaves of different genotypes 1 or 3 weeks after inoculation. Data are average of three replicates of representative from two independent experiments. Bars show standard errors. 
leaves were uredinia positive 16 days after inoculation. However, all three compounds (glyceollin, formononetin, and kaempferol) almost totally inhibited rust infection when applied both pre- and post-rust-spore-inoculation (Tables 2 and 3). In one case, postapplication of kaempferol had a positive reaction (Table 3), which could indicate either the ability of some spores to truly overcome the inhibitory effect of this compound or, most probably, that they must have been false positive. False positives could occur if the inoculum and phenolic droplet were not on the exact spot and, thus, the spores escaped the inhibitory effect of kaempferol.

If $P$. pachyrhizi spores were incubated overnight at room temperature in a medium containing the three selected phenolic

TABLE 1. Acetyl bromide lignin concentrations in cell walls of Phakopsora pachyrhizi inoculated and noninoculated (control) soybean leaves of different genotypes 1 or 3 weeks after inoculation

\begin{tabular}{lcr}
\hline & \multicolumn{2}{c}{ Lignin (percent of cell wall) ${ }^{\mathrm{z}}$} \\
\cline { 2 - 3 } Genotypes & 1 week & 3 weeks \\
\hline Williams control & $6.8 \pm 0.3$ & $5.8 \pm 0.2$ \\
Williams rust & $8.7 \pm 1.0$ & $10.4 \pm 0.7$ \\
PI230970 control & $6.1 \pm 0.2$ & $6.2 \pm 0.2$ \\
PI230970 rust & $9.0 \pm 0.8$ & $15.2 \pm 1.0$ \\
PI200492 control & $7.1 \pm 0.3$ & $7.0 \pm 0.2$ \\
PI200492 rust & $8.8 \pm 0.3$ & $9.8 \pm 0.5$ \\
PI462312 control & $5.8 \pm 0.3$ & $6.0 \pm 0.2$ \\
PI462312 rust & $8.1 \pm 0.4$ & $12.0 \pm 0.4$ \\
Williams 82 control & $6.1 \pm 0.2$ & $6.1 \pm 0.4$ \\
Williams 82 rust & $8.7 \pm 0.5$ & $10.9 \pm 0.7$ \\
\hline
\end{tabular}

${ }_{\mathrm{z}}$ Means and standard errors. compounds and quercetin at 50 or $100 \mathrm{nmol} / \mathrm{ml}$, the spore germination was inhibited compared with the untreated controls (Table 4). The greatest inhibitory effects (70 to $75 \%$ compared with the controls) were found in the presence of glyceollin, although quercetin and kaempferol also inhibited spore germination, while formonontin caused the least inhibition of spore germination.

TABLE 4. Germination of Phakopsora pachyrhizi urediniospores in the presence of phenolic compounds in medium

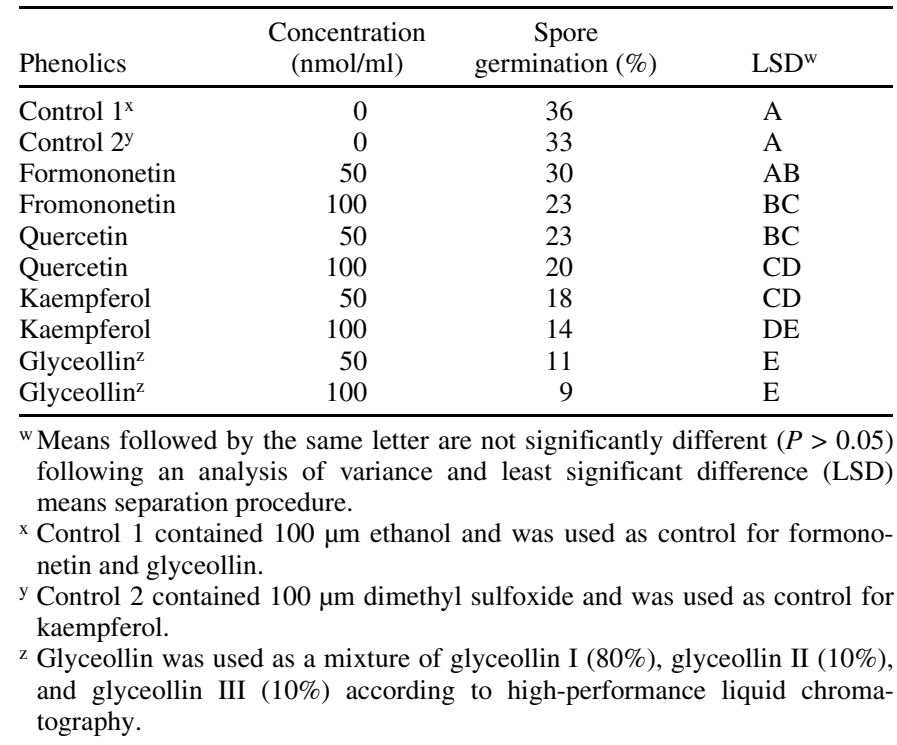

TABLE 2. Inhibition of rust infection on soybean leaves by phenolic compounds that were applied as a small drop before the spore inoculation (preinoculation of rust spores) scored 28 days after inoculation for urediniospore formation in five replicates

\begin{tabular}{|c|c|c|c|c|c|c|}
\hline \multirow[b]{2}{*}{ Phenolics } & \multirow[b]{2}{*}{ Concentration $(\mathrm{nmol} / \mathrm{ml})$} & \multicolumn{5}{|c|}{ Replicates $^{\mathrm{w}}$} \\
\hline & & R1 & $\mathrm{R} 2$ & R3 & $\mathrm{R} 4$ & R5 \\
\hline Control $1^{\mathrm{x}}$ & 0 & + & + & + & + & + \\
\hline Control $2^{\mathrm{y}}$ & 0 & + & + & + & + & + \\
\hline Kaempferol & 50 & - & - & - & - & - \\
\hline Kaempferol & 100 & + & - & - & - & - \\
\hline Kaempferol & 200 & - & - & - & - & - \\
\hline Formononetin & 50 & - & - & - & - & - \\
\hline Formononetin & 100 & - & - & - & - & - \\
\hline Formononetin & 200 & - & - & - & - & - \\
\hline Glyceollin $^{\mathrm{z}}$ & 50 & - & - & - & - & - \\
\hline Glyceollin $^{\mathrm{z}}$ & 100 & - & - & - & - & - \\
\hline
\end{tabular}

${ }^{\mathrm{w}} \mathrm{R} 1$ to $\mathrm{R} 5$ are replicates; + and - indicate the presence and absence, respectively, of urediniospores.

${ }^{x}$ Control 1 contained $100 \mu \mathrm{m}$ ethanol and was used as control for formononetin and glyceollin.

y Control 2 contained $100 \mu \mathrm{m}$ dimethyl sulfoxide and was used as control for kaempferol.

${ }^{\mathrm{z}}$ Glyceollin was used as a mixture of glyceollin I (80\%), glyceollin II (10\%), and glyceollin III (10\%) according to high-performance liquid chromatography.

TABLE 3. Inhibition of rust infection on soybean leaves by phenolic compounds that were applied as a small drop after the spore inoculation (postinoculation of rust spores) scored 28 days after inoculation for urediniospore formation in five replicates

\begin{tabular}{|c|c|c|c|c|c|c|}
\hline \multirow[b]{2}{*}{ Phenolics } & \multirow[b]{2}{*}{ Concentration $(\mathrm{nmol} / \mathrm{ml})$} & \multicolumn{5}{|c|}{ Replicates $^{\mathrm{w}}$} \\
\hline & & $\mathrm{R} 1$ & $\mathrm{R} 2$ & R3 & $\mathrm{R} 4$ & R5 \\
\hline Control $1^{\mathrm{x}}$ & 0 & + & + & + & + & + \\
\hline Control $2^{y}$ & 0 & + & + & + & + & + \\
\hline Kaempferol & 50 & - & - & - & - & - \\
\hline Kaempferol & 100 & - & - & - & - & - \\
\hline Kaempferol & 200 & - & - & - & - & - \\
\hline Formononetin & 50 & - & - & - & - & - \\
\hline Formononetin & 100 & - & - & - & - & - \\
\hline Formononetin & 200 & - & - & - & - & - \\
\hline Glyceollin $^{\mathrm{z}}$ & 50 & - & - & - & - & - \\
\hline Glyceollin $^{\mathrm{Z}}$ & 100 & - & - & - & - & - \\
\hline
\end{tabular}

${ }^{\mathrm{w}} \mathrm{R} 1$ to R5 are replicates; + and - indicate the presence and absence, respectively, of urediniospores.

${ }^{x}$ Control 1 contained $100 \mu \mathrm{m}$ ethanol and was used as control for formononetin and glyceollin.

y Control 2 contained $100 \mu \mathrm{m}$ dimethyl sulfoxide and was used as control for kaempferol.

${ }^{z}$ Glyceollin was used as a mixture of glyceollin I (80\%), glyceollin II (10\%), and glyceollin III (10\%) according to high-performance liquid chromatography. 
Collectively, these data show a much higher accumulation of glyceollin than of formononetin and the flavonoids quercetin and kaempferol in response to rust infection and a direct correlation between glyceollin levels and rust tolerance across the genotypes tested, as well as an absence of a correlation between the accumulation of formononetin and flavonoids and rust resistance. This could indicate that formononetin, quercetin, and kaempferol have little significance in the soybean plant response to rust infection despite their antifungal activity found in the spore germination tests. The isogenic genotypes Williams and Williams 82 show similar responses and are controls that reinforce the concept that formononetin, quercetin, and kaempferol are not directly involved in rust resistance.

Our results demonstrate that soybean plants respond to rust infection by induction of the synthesis of the phytoalexin glyceollin and the strengthening of the cell wall via enhanced deposition of the nondegradable aromatic polymer lignin, thus switching on these mechanisms of innate resistance. It is known that pathogens can rapidly adapt to resistance genes, reducing their effectiveness; however, the adaptation to the basal resistance in plants is much harder for pathogens to achieve. Therefore, plants with strong innate resistance (in our experiments, line PI230970) should have less disease over a longer period of time than plants with specific resistance only.

Expression of genes in response to soybean inoculation with $P$. pachyrhizi was recently analyzed using different soybean genotypes at different growth stages and timing of expression $(40,42,43)$. All of these experiments clearly showed that genes of the phenylpropanoid pathway and cell wall biosynthesis are rustregulated genes that are differentially expressed in inoculated leaves of susceptible and resistant genotypes, with the majority of the genes responding earlier during the infection, beginning $72 \mathrm{~h}$ after the inoculation time point in 3-week-old plants of resistant PI970230, than in susceptible genotype Embrapa-48 (40). Expression profiles of several genes that are involved in glyceollin biosynthesis (PAL, CHS, IFS2, and 2'-hydroxydihydrodaidzein reductase) and lignin biosynthesis (PAL and $O M T$ ) in soybean leaves inoculated with $P$. pachyrhizi showed a different time course for susceptible and resistant genotypes, which could explain the higher concentrations of this phytoalexin and lignin found in our experiments in rust-inoculated leaves of resistant plants compared with susceptible plants. A number of genes, such as genes encoding Myb domain-containing proteins, peroxidaselike protein, peroxidase precursors, and cytochrome P450 hydroxylases, were present in the soybean mRNA sets and were upregulated in rust-infected leaves. These genes could be associated with synthesis of phytoalexin, lignin, and other phenolics involved in plant defense and control resistance to rust infection (40). Interestingly, the expression profile of genes that participate in ammonium (substrate for the $P A L$-catalyzed reaction) transport resembled the temporal pattern of $P A L$ gene expression and other genes of phenylpropanoid synthesis (40), indicating that substrate availability for the initial reaction in the phenylpropanoid pathway can be important for plant defense against rust. Genes that control synthesis of glyceollin from daidzein are presently unknown, and expression of many unknown rust up- and downregulated genes has been reported $(40,42,43)$, so that some of them could be the genes that regulate the final steps of glyceollin biosynthesis. Induction of many general defense-related genes described in these publications (such as genes encoding jasmonic acid and salicylic acid biosynthesis-related proteins, protein kinases, ATP binding cassette transporters, the WRKY transcription factors, and others) could be a part of plant innate resistance in addition to phytoalexin accumulation and cell wall lignification found in our studies that could provide soybean tolerance to $P$. pachyrhizi.

Very little is known at present about the metabolic responses of soybean plants to $P$. pachyrhizi attack. Our studies indicate that an increase of synthesis of the soybean plant chemical weapons such as the antimicrobial compound glyceollin and cell-wall-fortifying compound lignin could help to improve soybean rust resistance. Thus, one way to achieve potentially higher levels of soybean resistance to rust could be genetic manipulation of metabolic events that could lead to production of glyceollin or lignin.

\section{ACKNOWLEDGMENTS}

This study was supported in part by funds from the Illinois Council on Food and Agricultural Research C-FAR; checkoff funds from the Illinois Soybean Association; the United Soybean Board; the Illinois Soybean Disease Biotechnology Center; the Illinois Agricultural Experiment Station; and the United States Department of Agriculture Cooperative State Research, Education and Extension Service, Hatch project no. 802309.

\section{LITERATURE CITED}

1. Albersheim, P., and Valent, B. S. 1978. Host-pathogen interaction in plants. Plants, when exposed to oligosaccharides of fungal origin, defend themselves by accumulating antibiotics. J. Cell Biol. 78:627-643.

2. Aoki, T., O’Donnell, K., Homma, Y., and Lattanzi, A. R. 2003. Suddendeath syndrome of soybean is caused by two morphologically and phylogenetically distinct species within the Fusarium solani species complex-F. virguliforme in North American and F. tucumaniae in South America. Mycologia 95:660-684.

3. Ayers, A., Ebel, J., Finelli, N., Berger, N., and Albersheim, P. 1976. Quantitative assay of elicitor activity and characteristics of the elicitor present in the extracellular medium of cultures of Phytophthora megasperma var. sojae. Plant Physiol. 57:751-759.

4. Azpilicueta, C. E., Zawoznik, M. S., and Tomaro, M. L. 2004. Phytoalexins synthesis is enhanced in groundnut plants inoculated with Bradyrhizobium sp. (Arachis). Crop Prot. 23:1069-1074.

5. Berger, S., Sinha, A. K., and Roitsch, T. 2007. Plant physiology meets phytopathology: plant primary metabolism and plant-pathogen interactions. J. Exp. Bot. 58:4019-4026.

6. Bhattacharyya, M. K., and Ward, E. W. B. 1985. Differential sensitivity of Phytophthora megasperma f sp glycinea to glyceollin isomers. Physiol. Mol. Plant Pathol. 27:299-310.

7. Bonde, M. R., Nester, S. E., Austin, C. N., Stone, C. L., Frederick, R. D., Hartman, G. L., and Miles, M. R. 2006. Evaluation of virulence of Phakopsora pachyrhizi and P. meibomiae isolates. Plant Dis. 90:708-716.

8. Bromfield, K. R. 1984. Soybean Rust Monograph, No. 11. American Phytopathological Society, St. Paul, MN.

9. Bromfield, K. R., and Hartwig, E. E. 1980. Resistance to soybean rust and mode of inheritance. Crop Sci. 20:254-255.

10. Bruce, R. J., and West, C. A. 1989. Elicitation of lignin biosynthesis and isoperoxidase activity by pectic fragments in suspension cultures of castor bean. Plant Physiol. 91:889-897.

11. Calvo, E. S., Kiihl, R. A. S., Garcia, A., Harada, A., and Hiromoto, D. M. 2008. Two major recessive soybean genes conferring soybean rust resistance. Crop Sci. 48:1350-1354.

12. Chakraborty, N., Curley, J., Frederick, R. D., Hyten, D. L., Nelson, R. L., Hartman, G. L., and Diers, B. W. Mapping and confirmation of a new allele at Rppl from soybean PI 594538A conferring RB lesion type resistance to soybean rust. Crop Sci. (In press.)

13. Dakora, F. D., and Phillips, D. A. 1996. Diverse functions of isoflavonoids in legumes transcend anti-microbial definitions of phytoalexins. Physiol. Mol. Plant Pathol. 49:1-20.

14. Dixon, R. A. 2001 Natural products and disease resistance. Nature 411:843-847.

15. Dixon, R. A., Howles, P. A., Lamb, C., He, X. Z., and Reddy, J. T. 1998. Prospects for the metabolic engineering of bioactive flavonoids and related phenylpropanoid compounds. Adv. Exp. Med. Biol. 439:55-66.

16. Ebel, J., and Grisebach, H. 1988. Defense strategies of soybean against the fungus Phytophthora megasperma f. sp. glycinea: A molecular analysis. Trends Biochem. Sci. 13:23-27.

17. Egea, C., Ahmed, A. S., Candela, M., and Candela, M. E. 2001. Elicitation of peroxidase activity and lignin biosynthesis in pepper suspension cells by Phytophthora capsici. J. Plant Physiol. 158:151-158.

18. Elfstrand, M., Sitbon, F., Lapierre, C., Bottin, A., and von Arnold, S. 2002. Altered lignin structure and resistance to pathogens in spi 2expressing tobacco plants. Planta 214:708-716.

19. Elmer, W. H. 2002. Influence of formononetin and $\mathrm{NaCl}$ on mycorrhizal colonization and Fusarium crown and root rot of asparagus. Plant Dis. 86:1318-1324 
20. Fischer, D., Ebenau-Jehle, C., and Grisebach, H. 1990. Phytoalexin synthesis in soybean: Purification and characterization of NADPH:2'hydroxydaidzein oxidoreductase from elicitor-challenged soybean cell cultures. Arch. Biochem. Biophys. 276:390-395.

21. Fukushima, R. S., and Hartfield, R. D. 2004. Comparison of acetylbromide spectrophotometric method with other analytical methods for determining lignin concentration in forage samples. Agric. Food Chem. 52:3713-3720.

22. Graham, T. L., and Graham, M. Y. 1991. Glyceollin elicitors induce major but distinctly different shifts in isoflavonoid metabolism in proximal and distal soybean cell populations. Mol. Plant-Microbe Interact. 4:60-68.

23. Graham, T. L., Kim, J. E., and Graham, M. Y. 1990. Role of constitutive isoflavone conjugates in the accumulation of glyceollin in soybean infected with Phytophthora megasperma. Mol. Plant-Microbe Interact. 3:157-166.

24. Hartman, G. L., Miles, M. R., and Frederick, R. D. 2005. Breeding for resistance to soybean rust. Plant Dis. 89:664-666.

25. Hartman, G. L., Sinclair, J. B., and Rupe, J. C. 1999. Compendium of Soybean Diseases. American Phytopathological Society Press, St. Paul, MN.

26. Hsieh, M. C., and Graham, T. L. 2001. Partial purification and characterization of a soybean $\beta$-glucosidase with high specific activity towards isoflavone conjugates. Phytochemistry 58:995-1005.

27. Huang, Y. H., and Hartman, G. L. 1998. Reaction of selected soybean genotypes to isolates of Fusarium solani f sp glycines and their culture filtrates. Plant Dis. 82:999-1002.

28. Ingham, J. L., Keen, N. T., Mulheirn, L. J., and Lyne, R. L. 1981. Inducibly-formed isoflavonoids from leaves of soybean. Phytochemistry 20:795-798.

29. Keen, N. T., Zaki, A. I., and Sims, J. J. 1972. Biosynthesis of hydroxyphaseollin and related isoflavonoids in disease-resistant soybean hypocotyls. Phytochemistry 11:1031-1039.

30. Killgore, E., and Heu, R. 1994. First report of soybean rust in Hawaii. Plant Dis. 78:1216.

31. Lange, B. M., Lapierre, C., and Sandermann, H. Jr. 1995. Elicitor-induced spruce stress lignin. Structural similarity to early developmental lignins. Plant Physiol. 108:1277-1287.

32. Levy, C. 2005. Epidemiology and chemical control of soybean rust in Southern Africa. Plant Dis. 89:669-774.

33. Li, S., Moore, W. F., Spinks, B. L., Wells, B. C., Sciumbato, G. L., Robinson, S. J., and Libous-Bailey, L. 2007. Occurrence of Asian soybean rust caused by Phakopsora pachyrhizi in Mississippi. Plant Health Progress, DOI:10.1094/PHP-2007-0917-02-BR.

34. Lozovaya, V. V., Lygin, A. V., Li, S., Hartman, G. L., and Widholm, J. M. 2004. Biochemical response of soybean roots to Fusarium solani f. sp. glycines infection. Crop Sci. 44:819-826.

35. Lozovaya, V. V., Lygin A. V., Zernova, O. V., Li, S., Hartman, G. L., and Widholm, J. M. 2004. Isoflavonoid accumulation in soybean hairy roots upon treatment with Fusarium solani. Plant Physiol. Biochem. 42:671679.

36. Lozovaya, V. V., Lygin, A. V., Zernova, O. V., Ulanov, A. V., Li, S., Hartman, G. L., and Widholm, J. M. 2007. Modification of phenolic metabolism in soybean hairy roots through down regulation of chalcone synthase or isoflavone synthase. Planta 225:665-679.

37. Markman, K. R. 1982. Techniques of flavonoid identification. Biological techniques series, Theherne, J. E., and Rubery P. H., eds. Academic Press, London.

38. Miles, M. R., Morel, W., Ray, J. D., Smith, J. R., Frederick, R. D., and
Hartman, G. L. 2008. Adult plant evaluation of soybean accessions for resistance to Phakopsora pachyrhizi in the field and greenhouse in Paraguay. Plant Dis. 92:96-105.

39. Moerschbacher, B. M., Noll, U. M., Gorrichon, L., and Reisener, H. J. 1990. Specific inhibition of lignification breaks hypersensitive resistance of wheat to stem rust. Plant Physiol. 93:465-470.

40. Mortel,-M.-van-de, Recknor, J. C., Graham, M. A., Nettleton, D., Dittman, J. D., Nelson, R. T., Godoy, C. V., Abdelnoor, R. V., Almeida, A. M. R., and Baum, T. J. 2007. Distinct biphasic mRNA changes in response to Asian soybean rust infection. Mol. Plant-Microbe Interact. 20:887-899.

41. Nicholson, R. L., and Hammerschmidt, R. 1992. Phenolic compounds and their role in disease resistance. Annu. Rev. Phytopathol. 30:369-389.

42. Panthee, D. R., Marois, J. J., Wright, D. L., Narvaez, D., Yuan, J. S., and Stewart, C. N., Jr. 2009. Differential expression of genes in soybean in response to the causal agent of Asian soybean rust (Phakopsora pachyrhizi Sydow) is soybean growth stage-specific. Theor. Appl. Genet. 118:359-370.

43. Panthee, D. R., Yuan, J. S., Wright, D. L., Marois, J. J., Mailhot, D., and Stewart, C. N., Jr. 2007. Gene expression analysis in soybean in response to the causal agent of Asian soybean rust (Phakopsora pachyrhizi Sydow) in an early growth stage. Funct. Integr. Genomics 7:291-301.

44. Pham, T. A., Miles M. R., Frederick, R. D., Hill, C. B., and Hartman, G. L. 2009. Differential response of resistant soybean genotypes to ten isolates of Phakopsora pachyrhizi. Plant Dis. 93:224-228.

45. Pourcel, L, Routaboul, J. M., Cheynier, V., Lepiniec, L., and Debeaujon, I. 2007. Flavonoid oxidation in plants: from biochemical properties to physiological functions. Trends Plant Sci. 12:29-36.

46. Salmeron, J. M., and Vernooij, B. 1998. Transgenic approaches to microbial disease resistance in crop plants. Curr. Opin. Plant Biol. 1:347352.

47. Sasaki, M., Yamamoto, Y., and Matsumoto, H. 1996. Lignin deposition induced by aluminum in wheat (Triticum aestivum) roots. Physiol. Plant. 96:193-198.

48. Scheel, D. 1998. Resistance response physiology and signal transduction. Curr. Opin. Plant Biol. 1:305-310.

49. Schneider, R. W., Hollier, C. A., Witham, H. K., Palm, M. E., McKemy, J. M., Hernandez, J. R., Levy, L., and DeVries-Paterson, R. 2005. First report of soybean rust caused by Phakopsora pachyrhizi in the continental United States. Plant Dis. 89:774.

50. USDA. 2009. Integrated Pest Management-Pest Information Platform for Extension and Education. Online. Available at http://sbr.ipmpipe.org/ cgi-bin/sbr/public.cgi (verified June 1, 2009).

51. Vance, C. P., Kirk, T. K., and Sherwood, R. T. 1980. Lignification as a mechanism of disease resistance. Annu. Rev. Phytopathol. 18:259-288.

52. Walter, M. H. 1992. Regulation of lignification in defense. Pages 327-352 in: Plant Gene Research-Genes Involved in Plant Defense. T. Boller and F. Meins, eds. Springer-Verlag, New York.

53. Weisshaar, B., and Jenkins, G. I. 1998. Phenylpropanoid biosynthesis and its regulation. Curr. Opin. Plant Biol. 1:251-257.

54. Yorinori, J. T., Paiva, W. M., Frederick, R. D., Costamilan, L. M., Bertagnolli, P. F., Hartman, G. L., Godoy, C. V., and Nunes, J., Jr. 2005. Epidemics of soybean rust (Phakopsora pachyrhizi) in Brazil and Paraguay from 2001-2003. Plant Dis. 89:675-677.

55. Zahringer, U., Ebel, J., and Grisebach, H. 1978. Induction of phytoalexin synthesis in soybean: Elicitor-induced increase in enzyme activities of flavonoid biosynthesis and incorporation of mevalonate into glyceollin. Arch. Biochem. Biophys. 188:450-455. 